\title{
Representações sociais sobre o judô no Brasil veiculadas pela revista Veja (anos 1970/1980)
}

\author{
Social representations about the Judo in Brazil veiculated by the \\ Veja magazine (years 1970/1980)
}

DOI: http://dx.doi.org/10.36453/2318-5104.2018.v16.n1.p129

\author{
Alice Beatriz Assmann, Josiana Ayala Ledur, Tuany Defaveri Begossi, \\ Janice Zarpellon Mazo \\ Universidade Federal do Rio Grande do Sul (UFRGS)
}

\begin{abstract}
RESUMO
A participação do Brasil na modalidade esportiva judô em Jogos Olímpicos (JO) iniciou na década de 1970. Diferentes meios de comunicação veicularam notícias sobre o evento e, dentre estes, se destaca a revista Veja. Diante disso, o objetivo do estudo é investigar as representações sociais constituídas/compostas pela revista Veja sobre a participação dos atletas brasileiros de judô, nas edições dos JO de 1972 até 1988. Para tanto, foram coletadas reportagens relacionadas ao fenômeno estudado, nas edições da revista Veja, disponibilizadas em acervo digital. A interpretação das informações culminou na construção de três categorias de análise, a saber: a) O judô no Brasil; b) A conquista das medalhas; c) c) O judô brasileiro olímpico. Foi evidenciado que, inicialmente, a participação do judô brasileiro em Jogos Olímpicos era associada a uma identidade japonesa. Ademais, buscava-se desvincular representações de insuficiência e fracasso da identidade brasileira. No decorrer dos anos, os discursos veiculados na revista foram sendo transformados, possivelmente, em decorrência das medalhas conquistadas pelos judocas, e o judô, passou a ser representado como um esporte nacional. Por fim, ressalta-se que a revista Veja por ser um instrumento midiático, deve ser analisada com criticidade, sendo necessário atentar-se para a superficialidade e parcialidade dos discursos e suas repercussões.
\end{abstract}

PALAVRAS-CHAVE: Jogos Olímpicos; Judô; Representações Sociais; Artes Marciais; Lutas.

\section{ABSTRACT}

The participation of Brazil on the sport discipline judo at Olympic Games (OG) began in the 1970s. Different print media, at that time, circulated informations about the event and, among them, Veja magazine stands out. This study aims to investigate social representations constituted/composed by Veja Magazine about the participation of Brazilian judo athletes, since the 1972 until the 1988 OG event. Therefore, reports concerning the object of this study were collected on Veja magazine copies, available in a digital collection. The interpretation of the informations culminated in three categories of analysis: a) Judo in Brazil; b) The achievement of the medals; and, c) The brazilian olympic judo. It was evidenced that, initially, the participation of the Brazilian judo at Olympic Games was associated with a Japanese identity. Furthermore, it seems to be managed to untie representations of insufficiency and defeat from a brazilian identity. Over the years, as a possible outcome from the medals won by Judo athletes, the speeches were modified and the Judo has come to be represented as a national sport. Lastly, it should be pointed out that Veja, as a media instrument, must be analyzed with criticism, being necessary to be aware of the superficiality and partiality of the discourses and their repercussions.

KEYWORDS: Olympic Games; Judo; Social Representations; Martial Arts; Fighting sports. 


\section{INTRODUÇÃO}

O Judô passou a fazer parte dos Jogos Olímpicos (JO) no ano de 1964, em Tóquio (Japão), na condição de "esporte de apresentação". Na ocasião foi apresentado apenas por atletas masculinos e o Brasil esteve representado por Lhofei Shiozawa. A despeito de ter sido exibido em Tóquio, a modalidade não fez parte do programa olímpico da edição seguinte, realizada na cidade do México, em 1968, e retornou aos JO apenas quatro anos depois (NUNES, 2011). A inclusão do Judô enquanto modalidade oficial dos JO sucedeu na edição realizada em Munique (Alemanha), no ano de 1972, na categoria masculina ${ }^{1}$. Nesta edição, o Brasil participou da competição com o atleta Chiaki Ishii, japonês naturalizado brasileiro, que conquistou uma medalha de bronze na modalidade ${ }^{2}$. Na década seguinte, judocas brasileiros conquistaram mais medalhas em JO. Dentre os que alcançaram um lugar no pódio, destaca-se Aurélio Miguel, atleta que obteve a primeira medalha de ouro na modalidade, conquistada nos JO de Seul (1988).

A participação de atletas nos JO e, principalmente, a conquista de medalhas, é destacada pela mídia brasileira que constrói e/ou reproduz representações a seu respeito. Os atletas, por sua vez, muitas vezes são mencionados como heróis, refletindo um ideal a ser desejado e conquistado e, por outro lado, também são vistos como um produto rentável, com potencial de propaganda para patrocinadores e seus produtos (TEIXEIRA; DUARTE, 2014). Na mídia impressa, as revistas são um dos exemplos da produção de representações sobre a imagem de atletas olímpicos, bem como do universo de consumo que pode levar o atleta a ser objeto de "venda" de marcas de patrocinadores (AMARO, 2014, RUBIO, 2002).

No presente estudo 3 o foco recai sobre a revista Veja, publicação criada em 1968 que, desde então, conquistou posição de destaque no que diz respeito à produção jornalística brasileira, visto que é a quarta revista semanal de informação do mundo, com um total de 1,1 milhão de exemplares impressos semanalmente, antecedida somente pelas revistas americanas Time, Newsweek e U.S. News. Logo, nas primeiras décadas de sua veiculação, a revista Veja, para além de uma mídia construtora de retratos de fatos jornalísticos, tornouse um conceito, uma marca que carrega valores e atributos, guiados por uma ótica alusiva aos princípios estipulados pela organização a que pertence - o Grupo Abril. A representatividade da Veja, desta forma, não se limita à tiragem, vai além, em um país que concentra formadores de opinião em uma pequena elite. Ademais, destaca-se que no ano de 2010, a revista contava com mais de sete milhões de leitores (BARROS, 2010).

Ao considerar que a referida revista alcançou, no século XXI, um número significativo de leitores, o presente estudo tem como objetivo investigar as representações sociais constituídas/compostas pela revista Veja sobre a participação dos atletas brasileiros de Judô, nas edições dos Jogos Olímpicos de 1972 até 1988. Justifica-se o recorte temporal inicial, referente ao ano de 1972, pois este foi o momento em que ocorreu a primeira competição oficial da modalidade nos $\mathrm{JO}$ e houve a participação de judocas do Brasil. A demarcação temporal se encerra em 1988, pois o ano assinala a conquista da primeira medalha olímpica de ouro por um judoca brasileiro.

A despeito da visibilidade da revista Veja, temos ciência de que estamos diante de uma versão divulgada pela mídia, a qual é formadora de opiniões, saberes, normas, valores e subjetividades que são direcionados para o interlocutor por meio de mensagens. De tal modo, um grande contingente de pessoas avista determinadas concepções de mundo através das lentes da revista e por meio deste viés diversas representações são construídas e disseminadas. Para Amorim (2014) a mídia é considerada o Quarto Poder fazendo frente ao Legislativo, Executivo e Judiciário, em termos de influência política, sendo a maior fonte de informação e entretenimento para a população. Munida deste "poder", pode atuar como um meio de controle social, que através da manipulação de informações destinadas à sociedade, pode tanto interferir nos modos de pensar e de opinar (SILVA; SANTOS, 2009). De acordo com Coimbra (2001, p. 2), os diferentes artefatos midiáticos não

\footnotetext{
${ }^{1}$ Vale mencionar que a participação das mulheres nas competições de judô nos JO ocorreu somente 20 anos depois dos homens, na edição de BarceIona (Espanha), em 1992 (NUNES; KOSMANN; SHOURA, 2005). A primeira judoca brasileira a ganhar a medalha olímpica foi Ketleyn Quadros, nos JO de Pequim em 2008. Ela também é a primeira atleta brasileira a conquistar medalha em um esporte individual.

${ }^{2}$ As primeiras medalhas obtidas por brasileiros natos em JO se deu na edição de 1984, em Los Angeles, nos Estados Unidos (NUNES, 2011).

${ }^{3}$ Este estudo faz parte de um amplo projeto de pesquisa intitulado: “Cenários Históricos e socioculturais dos Esportes e da Educação Física no Rio Grande do Sul - Brasil", que busca desenvolver estudos sócio-históricos sobre o Esporte e a Educação Física, no que tange às particularidades do Rio Grande do Sul. Nessa direção, pretende-se apresentar o contexto sul-rio-grandense por meio das práticas e representações sociais, bem como culturais e esportivas, de clubes, personagens e atletas em competições nacionais e eventos esportivos internacionais, como, por exemplo, Jogos Olímpicos, Jogos Paralímpicos, Jogos Pan-Americanos e Jogos Parapan-Americanos. Os procedimentos metodológicos utilizados para o desenvolvimento das investigações são a produção e interpretação de fontes orais, impressas e imagéticas
} 
indicam somente "o que pensar, o que sentir, como agir, mas principalmente orientam sobre o que pensar, sobre o que sentir".

Cabe salientar, que neste estudo utilizamos o conceito de representação social a partir das concepções elaboradas, especialmente, por Serge Moscovici (2015) e Denise Jodelet (2001). O conceito de representação social foi nomeado por Moscovici (2015), a partir de uma releitura da concepção de representação coletiva de Émile Durkheim e, desde então, tem sido empregado em distintos estudos, por diferentes autores, como conceito chave na busca por apreender compreensões de mundo. Denise Jodelet, reconhecida estudiosa e difusora da teoria das representações sociais, compreende o conceito como "o produto e processo de uma atividade de apropriação da realidade exterior ao pensamento, e da elaboração psicológica e social da realidade" (JODELET, 2001, p. 22).

A elaboração de uma representação social é edificada de forma coletiva, permeando as relações sociais e as maneiras como os indivíduos compreendem, administram ou enfrentam o mundo. Podem, assim, estabelecer relações de pertencimento a determinados grupos, por meio de símbolos e significações que orbitam no imaginário social. Enquanto produtos de um processo histórico em constante construção, as representações sociais são fenômenos dinâmicos e estão, também, sujeitas a transformações e ressignificações (MOSCOVICI, 2015).

Assim, as representações sociais encontram-se presentes em discursos, palavras, mensagens e imagens midiáticas, enraizadas em condutas e direcionadas por espaços sociais e concepções, concernentes ao tempo vivido (JODELET, 2001). Tais representações podem atuar de formas mais ou menos determinantes, na orientação de comportamentos de indivíduos e de seus coletivos, nos respectivos meios sociais. Segundo Missias-Moreira (2017, p. 15), trata-se de compreender "como se constitui e como se operam os sistemas de referência, que utilizamos para qualificar grupos e pessoas, e para compreender e interpretar os acontecimentos do dia-a-dia".

A partir desses pressupostos, os jornais podem ser concebidos enquanto processos de comunicação, que produzem e circulam representações sociais. Essas, por sua vez, são apresentadas na forma de discursos e narrativas, que operam no e para o imaginário coletivo, dando sustentação aos saberes do cotidiano (MOSCOVICl, 2015). Deste modo, estabelecem-se como um meio, dentre tantos outros, de apreender como determinado grupo de pessoas percebe, entende e compartilha representações de mundo, bem como a forma que constituem uma compreensão comum da realidade. Ressalta-se que os discursos disseminados e as representações erigidas, não podem ser entendidos enquanto um arranjo padronizado, que remete a uma compreensão única e generalizada do cotidiano. Diferentes meios, assim como diferentes grupos, podem apresentar sistemas interpretativos distantes ou, até mesmo, divergentes sobre a mesma realidade. Através de veículos midiáticos, como a revista Veja, foco das análises desenvolvidas nesse estudo, representações são construídas e ressignificadas por aqueles que selecionam e redigem as informações veiculadas, bem como, por quem as recebe e delas se apropria.

\section{PROCEDIMENTOS METODOLÓGICOS}

Para compor a investigação, elegemos a pesquisa documental enquanto estratégia metodológica. No presente estudo, o foco versará sobre as representações sociais dos judocas brasileiros, nos JO, pela ação da mídia impressa, mais especificamente, sobre aquelas veiculadas pela revista Veja. Para tanto, foi realizada a coleta de informações nas edições desta revista, disponíveis em seu Acervo Digital, onde estão digitalizadas a partir do ano 1968, correspondente ao primeiro exemplar. A escolha desta fonte se justifica por ser um proeminente meio de comunicação a nível nacional e, sobretudo, por ter produzido matérias relacionadas aos JO. Devido ao nosso recorte investigativo iniciar em 1972, as buscas empreendidas partem desse ano. Os demais anos consultados correspondem às edições em que ocorreram os JO, encerrando-se em 1988, quando o judô brasileiro ganhou maior notoriedade. Nos anos demarcados para o estudo foi feita uma busca por termos, a saber: Judô e Jogos Olímpicos. Desta primeira busca foram selecionadas 14 reportagens advindas da sessão denominada "Esportes, Olimpíadas" e outras de menor repercussão.

Após a coleta das reportagens, as informações foram agrupadas por elementos de mesma classe e organizadas em pastas para serem posteriormente analisadas, de acordo com a técnica de análise de 
conteúdo, proposta por Bardin (2011), pois esta considera o discurso como um todo, visando identificar e classificar os diferentes significados encontrados nos documentos. Cabe ressaltar que a análise de conteúdo, ainda é referenciada como um conjunto de técnicas de análise das comunicações, que utiliza procedimentos sistemáticos e objetivos de descrição do conteúdo das mensagens, pressupondo-se as seguintes fases: 1) Préanálise; 2) Exploração do material; e, por fim, 3) O tratamento dos resultados: a inferência e a interpretação.

Antes de iniciarmos as etapas de análise, e a fim de facilitar a organização do material consultado, cada reportagem teve seu título anotado, com suas respectivas edições, sessões e autores (quando indicados), o ano e a página, conforme as orientações de Pimentel (2001). Após, procedemos com a etapa de pré-análise, que envolveu uma leitura flutuante das fontes selecionadas. A segunda etapa, nomeada exploração do material, consistiu em operações de codificação, em que foram levados em conta os recortes textuais extraídos da revista, em unidades de registro, para posterior classificação das informações em categorias temáticas. Com relação a última etapa, referente ao tratamento dos resultados, as informações foram orientadas tanto pela inferência, quanto pela interpretação, ou seja, fomos em busca de captar os conteúdos visíveis e latentes, contidos em todo o material coletado (BARDIN, 2011).

Cabe salientar que a utilização de reportagens, tais como as da revista Veja, enquanto fonte de pesquisa, requer alguns cuidados metodológicos, sobretudo, por se tratar de uma produção sujeita a parcialidades, manipulações e interesses (LUCA, 2010). Conforme aponta Dalmáz (2002), os autores de reportagens tanto interpretam os fatos, como realizam uma seleção dos acontecimentos na construção da informação. Tal processo caracteriza alguns dos mecanismos utilizados pela imprensa, para criar uma realidade. Por conseguinte, fazse necessário interrogar estas fontes, ou seja, traçar as características fundamentais que as constituem como meio de comunicação (ZICMAN, 1985). Ao adotar esta estratégia, pretende-se conhecer o tipo de impacto por elas alcançado, público alvo, bem como o contexto temporal, histórico-social presente (CAMPOS, 2012).

Para além das cautelas que cercam a utilização dos periódicos semanais como fontes privilegiadas de análise, é preciso, também, atentar para as inclinações da própria subjetividade do pesquisador. Ressalta-se, que o enfoque lançado sobre as informações foi guiado pelo referencial teórico acerca das representações sociais. Esta abordagem, contudo, é sempre posicionada no tempo e no espaço, social e culturalmente, destarte, é impossível negar a presença do sujeito pesquisador na escrita do estudo.

Na sequência apresentamos os resultados e a discussão decorrentes da análise de três categorias elencadas para este estudo: a) O judô no Brasil; b) A conquista das medalhas; c) O judô brasileiro olímpico.

\section{RESULTADOS E DISCUSSÃO}

A partir dos procedimentos de análise aplicados nas reportagens, foram estabelecidas categorias que compõem este estudo. Estas, por sua vez, não se encerram em sua própria definição, mas relacionam-se umas com as outras, cunhando um processo histórico e social que não é construído linearmente. Ressaltamos que as categorias, por vezes, se embaraçam, contudo, buscam organizar as interpretações suscitadas através das representações sociais sobre o judô, identificadas na revista Veja entre 1972 e 1988.

Diante disso, a composição dos tópicos apresentados abaixo permitiu o acompanhamento das transformações incididas sobre a modalidade esportiva em questão, bem como de seus atletas praticantes, durante o período eleito ao estudo (1972-1988). As informações resultantes do processo analítico, amparado pelo referencial teórico das representações sociais (JODELET, 2001; MOSCOVICI, 2015), foram confrontadas com a literatura examinada, com o intuito de ampliar o entendimento acerca da temática estudada. Na sequência, apresentamos os resultados por meio das categorias de análise, as quais expõem o processo de mudança da modalidade, por meio de suas representações.

\section{O judô no Brasil}

A primeira participação oficial de representantes brasileiros no judô foi assunto de reportagens da revista Veja, nos meses que decorreram os JO de 1972. Nestas, o judô e seus atletas são representados socialmente enquanto um grupo à parte: "uma ilha de japoneses no meio de 122 brasileiros" (A OUTRA MEDALHA, 13 set. 
1972, p. 72). Constata-se a produção de uma diferenciação, a fim de atribuir um sentido de distanciamento cultural e identitário, marcando o nós "brasileiros" e o eles "japoneses". "Entre si falam só japonês", reforça a matéria (A OUTRA MEDALHA, 13 set. 1972, p. 72), apropriando-se de uma marcação identitária de forte legitimidade, a língua, dando a ler determinado significado.

Associado às representações sociais que tencionaram a construção de um distanciamento identitário, também se sobressaiu à intenção da reportagem em dissociar a ideia do fracasso, à de nação brasileira. Sobre este ponto, evidenciamos que, enquanto a reportagem do mês de agosto de 1972, abordava o "começo da organização" da delegação brasileira para os JO, estampando uma fotografia de Chiaki Ishii, judoca representante do Brasil, cuja preparação foi complementada "na própria terra dos campeões mundiais, o Japão" (O COMEÇO DA ORGANIZAÇÃO, 23 ago. 1972, p. 45), as demais reportagens hostilizam de certa forma, a participação dos atletas deste esporte, sobretudo em razão de seus desempenhos nos JO. Por vezes, tais notícias parecem se referir a competidores não brasileiros, especialmente em razão das tensões produzidas no discurso.

Este assunto pode ser averiguado, por exemplo, na reportagem que trata da medalha de bronze, apropriando-a de um sentido de "derrota". Ainda, os judocas são adjetivados como "Os inexperientes de Munique", expressão esta, que deu título à reportagem sobre a conquista da primeira medalha brasileira no judô - medalha de bronze, do japonês naturalizado Chiaki Ishii. Para além de salientar certa incapacidade por parte dos atletas, o colunista conclui ainda, em tom de descaso: "Não era muito, mas foi comemorado com a alegria de quem, enfim, ganha alguma coisa" (OS INEXPERIENTES DE MUNIQUE, 6 set. 1972, p. 97).

Para o colunista, conforme é possível observar, o bronze no judô não significou "muito". Esse discurso revela a ênfase nas derrotas em detrimento das conquistas, como o faz também no seguinte trecho: "E nas semifinais de judô Chiaki Ishii perdeu a medalha de prata para o inglês David Starbrook" (APRENDER ANTES DE COMPETIR, 13 set. 1972, p. 68). As derrotas, por sua vez, são atribuídas à inexperiência, à falta de preparo e à distração dos atletas antes da luta: "o meio pesado Chiaki Ishii distraía-se lendo um livro em japonês, de aventuras de samurais" (A OUTRA MEDALHA, 13 set. 1972, p. 72). Percebe-se que a reportagem redigida na época não cogitou a possibilidade da leitura de um livro ser utilizada pelo judoca como estratégia para outros fins como, por exemplo, de redução da ansiedade pré-competitiva.

Não obstante a forma que o colunista escolheu para retratar a atuação brasileira nas competições de judô nos JO de 1972, apontamos outra possibilidade de interpretação. Ao invés de se dar destaque para "perda da medalha de prata" conforme está posto, destacamos que Chiaki Ishii conquistou o bronze para o Brasil, sendo esta, a primeira medalha obtida pela modalidade em JO e, por conseguinte, significando um marco para a História do Esporte no país. Afinal, aqueles denominados "inexperientes de Munique", por outro lado, foram pioneiros e ocuparam pela primeira vez um lugar no pódio do judô, carregando consigo a bandeira do Brasil.

Ao que nos pareceu, as reportagens publicadas na época buscaram construir uma representação social, que desvinculava a ideia de fracasso à de nação brasileira. Esta constatação, por sua vez, não vincula necessariamente a ideia de fracasso a uma ou a outra nação, ou seja, não é porque as reportagens desvincularam o fracasso da identidade brasileira, que a ligam, de outra forma, a identidade japonesa. Esse distanciamento da ideia de derrota do contexto nacional estava relacionado aos discursos do governo brasileiro naquele período, especialmente associados a ideologias advindas da conformação política em curso - a ditadura civil-militar, e que buscava consolidar o Brasil enquanto uma potência esportiva mundial.

Assim, a percepção de uma delegação brasileira sob uma nova conformação, mais "madura e organizada", foi anunciada dias antes do início da competição (O COMEÇO DA ORGANIZAÇÃO, 23 ago. 1972, p. 45). Contudo, a posição ocupada pelo Brasil no ranking de medalhas foi o 41 ํㅡos JO de 1972, devido à conquista de das duas medalhas de bronze. Tendo em vista os ideais, especialmente políticos, em voga na época, tais conquistas não significavam muito: "não para um país, mas para um regime que apostava na megalomania como agente de educação das massas e consequente engrandecimento da nação" (OLIVEIRA, 2012, p. 160).

Se para os objetivos políticos do regime autoritário vigente a conquista do bronze não teve grande serventia, para o judô, enquanto esporte que buscava consolidar-se no país, a medalha favoreceu a institucionalização da Confederação Brasileira de Judô. A entidade esportiva, fundada em 1969, foi reconhecida pelo governo brasileiro em 1972, após a vitória de Chiaki Ishii (PARIZOTTO et al., 2017). Nunes (2011) em sua

${ }^{4}$ A competição teve início no dia 26 de abril e foi encerrada em 11 de setembro. 
tese de doutorado referiu que as contribuições destes anos iniciais do judô foram marcadas por importantes transformações no cenário esportivo brasileiro. O autor (2011) salienta que Chiakii Ishii, além de ser o primeiro atleta a conquistar uma medalha para o Brasil em JO, ainda detinha um relevante conhecimento sobre o judô influenciando, posteriormente, várias gerações de judocas e professores.

\section{A conquista das medalhas}

As primeiras reportagens publicadas sobre os JO de Munique (1972) apresentaram em seu escopo expectativas pela conquista de medalhas na competição, especialmente aquela que estampou a imagem de Chiaki Ishii, evidenciando sua preparação "na própria terra dos campeões mundiais", na época o Japão (O COMEÇO DA ORGANIZAÇÃO, 23 ago. 1972, p. 45). Sem embargo, conforme aventamos no tópico anterior, alguns colunistas da Veja, não deram muito crédito aos judocas brasileiros e aos resultados obtidos por eles, uma vez que, a medalha de bronze de 1972 parece ter representado um insucesso para o esporte. Ainda que de forma gradual, esse discurso paulatinamente foi modificado nas páginas da revista Veja.

A medalha conquistada por Chiaki Ishii, em 1972 foi conferida "ao acaso", ao lado de vitórias brasileiras anteriores. Na reportagem veiculada em 1976, o colunista evidencia a trajetória olímpica brasileira, dando ênfase às conquistas que, segundo o que consta, "pareciam acontecer por acaso". Figurando ao lado do trecho sobre Chiaki Ishii, destaca-se outro a respeito da equipe de brasileiros que viajou para participar dos Jogos Olímpicos da Antuérpia (Bélgica), "num navio de terceira classe", em 1920. "A turma", conforme são denominados os atletas do tiro que participaram desse evento, "havia sido reunida ao acaso" e, apesar da precariedade do alojamento onde ficaram na Antuérpia, conquistaram medalhas. Os atletas foram Guilherme Paraense, medalha ouro no tiro revólver, Afrânio Costa que obteve a prata em pistola e, a equipe, por sua vez, conquistou medalha de bronze em pistola livre. O "acaso" também foi conferido para a conquista da medalha de bronze pela seleção masculina de basquetebol, nos JO de Londres, em 1948. Segundo informações contidas na reportagem, a equipe sequer iria ser enviada para a competição mundial, visto os "péssimos resultados obtidos na América do Sul" (BRASILEIROS: AS MEDALHAS GANHAS POR ACASO, 28 jul. 1976, p. 114). Observa-se que mesmo a reportagem atribuindo crédito ao "acaso", ao invés do empenho dos atletas, foram referenciadas trajetórias brasileiras vitoriosas em Jogos Olímpicos.

Contudo, na mesma matéria, o resultado de Chiaki Ishii nos JO de Munique, aludido como "um lutador de judô formado basicamente no Japão", foi utilizado como justificativa para sua renúncia às competições: "pretendia ganhar a medalha de ouro. Insatisfeito com a de bronze, abandonou as competições" (BRASILEIROS: AS MEDALHAS GANHAS POR ACASO, 28 jul. 1976, p. 114). Nessa reportagem, conforme é possível notar, o discurso de abandono da prática parte do próprio atleta que, após frustrar-se nos JO de Munique, decidiu afastar-se da modalidade. Além disso, um traço recorrente nas reportagens consultadas é a representação do fracasso esportivo. Esta característica pode ser observada, por exemplo, nos títulos e subtítulos das reportagens, que tratavam de noticiar o desempenho dos atletas brasileiros, na modalidade de judô, nos JO de Montreal, em 1976. A notícia com subtítulo "só surras", salientava "a magra colheita brasileira" na competição, sendo este o título da reportagem. Publicada em quatro de agosto de 1976, fazia referência ao judoca meio pesado Carlos Alberto Pacheco, aquele que "durou mais" nos Jogos de Montreal (SÓ SURRAS, 4 ago. 1976, p. 100).

Durante as primeiras edições dos $J 0$ em que o judô se fez presente, o Brasil não possuía atletas com significativa projeção mundial. Contudo, a conquista de medalhas em campeonatos internacionais começava a alterar este quadro. No ano dos JO de Moscou, em 1980, uma matéria sobre os judocas brasileiros com possibilidade de medalhas na competição mundial, com menção a "Luis Shinohara, campeão pan-americano de 1979", e "Walter Carmona, peso médio, 3o lugar no campeonato mundial de Paris", afirmava: "a guerra esquentou"5 (A GUERRA ESQUENTOU, 23 abr. 1980).

Mesmo com a recorrência de vitórias em competições internacionais, o desempenho positivo dos atletas do judô brasileiro parecia ser visto, ainda, com surpresa pela imprensa internacional. Este foi o caso retratado pela revista Veja com relação à medalha de prata de Douglas Vieira, nos JO de Los Angeles, em 1984. De acordo com a revista, o desempenho do atleta foi recebido como algo inesperado, mencionando a perplexidade

\footnotetext{
${ }^{5}$ Nos JO de Moscou (na época União Soviética), em 1980, as medalhas ficaram por conta dos atletas da vela, da natação e do atletismo.
} 
dos jornalistas canadenses diante da conquista: "Como é que pode um desconhecido chegar à final de uma Olimpíada? ", indagavam. Naquela edição, o Brasil teve seu melhor desempenho em JO, desde 1920, quando angariou a primeira medalha de ouro ${ }^{6}$. Dentre oito medalhas conquistadas em 1984, três pertenciam ao judô, sendo uma de prata e duas de bronze ${ }^{7}$. As "vitórias no tatame" foram reportadas em uma extensa matéria na revista Veja (VITÓRIAS NO TATAME, 15 ago. 1984, p. 60).

A trajetória de conquistas do judô brasileiro em campeonatos mundiais, fez com que o foco das reportagens noticiadas pela Veja fosse realinhado. O que começou a se tornar perceptível a partir desta fase, foi a construção, ainda tímida, de uma representação social que atrelava o mérito por medalhas no judô, a uma identificação com a nação brasileira. Os atletas da modalidade eram citados com suas identidades vinculadas aos estados brasileiros, reforçando uma representação regionalista. Douglas Viera, medalha de prata, segundo a revista, era o "mineiro", enquanto Luis Onmura, medalha de bronze, foi reportado como "paulista", embora "filho de um modesto imigrante japonês" (VITÓRIAS NO TATAME, 15 ago. 1984, p. 60). Desse modo, a Veja inicia uma variação de seu discurso, no momento em que o judô brasileiro começa a ocupar lugar no pódio, em campeonatos mundiais buscando, para tanto, aproximar os atletas de uma identidade nacional/regional. Tal característica, de outra forma, não desvincula a presença também de uma identidade japonesa, uma vez que, esta se localiza na essência do judô, enquanto prática corporal.

Nota-se que o atleta Douglas Vieira, apesar de ser designado como mineiro pela revista em duas reportagens distintas, é natural de Londrina, no Paraná, e foi o primeiro brasileiro nato a participar de uma final olímpica no judô, ocorrida na edição dos JO de Los Angeles, em 1984. Este foi considerado um ano marcante para o judô brasileiro, pois, além da medalha de prata de Douglas Vieira, Luiz Onmura e Walter Carmona também haviam conquistado medalhas de bronze um dia antes. A medalha de prata conquistada foi considerada um resultado excepcional para os padrões da época e, juntamente com as demais conquistas, abalizou a melhor campanha do judô brasileiro até então (NUNES, 2011; NUNES; RUBIO, 2012).

Para além de buscar estabelecer relação entre os atletas do judô e uma identidade nacional, as modificações do discurso nas reportagens da Veja também ratificaram o interesse que tais vitórias "despertaram" nos telespectadores brasileiros. Trechos como: "com essas vitórias, o judô nacional despertou de um momento para o outro o interesse dos telespectadores que, no Brasil nem sequer sonhavam com uma única medalha saída deste esporte" (VITÓRIAS NO TATAME, 15 ago. 1984, p. 60), demonstraram um interesse de produzir uma conversão, de certa forma, daquelas percepções noticiadas em 1972. Na edição dos JO de 1984, mesmo que os torcedores brasileiros estivessem mais atraídos pelos jogos de futebol e de voleibol, ou interessados em acompanhar as passadas do corredor Joaquim Cruz, percebeu-se certo reconhecimento do "brilhante desempenho olímpico de três campeões dos tatames". Observa-se, desta forma, o início de uma mudança das percepções da revista Veja, com relação ao esporte. Enquanto que em 1972 a revista Veja distinguia o judô culturalmente, pelas representações identitárias japonesas, a partir das conquistas do esporte em 1984, legitimava-o como "brasileiro" e esporte "nacional", discurso condizente com as estratégias do governo militar.

Segundo Taborda de Oliveira (2012, p. 164-5), a relação entre política e esporte funcionava "por um lado, contribuindo para o cimento da coesão, harmonia e alegria nacionais, ajudando a consolidar o "brasileiro" como um vencedor; por outro, contribuindo para refinar a presença do Brasil nos trilhos do progresso, da riqueza e da modernidade", sendo a grande imprensa meio de veiculação de tais ideais. Nos anos de vigência do regime ditatorial, Rautenberg (2011), ao tratar de discursos veiculados acerca das guerrilhas e das relações de mercado naquele período, define a revista Veja enquanto "lugar de busca e construção de consenso, e também de articulação de interesse" (p. 82), ajustando-se às pretensões do momento político e social. Tendo como base essa afirmativa de Rautenberg (2011), podemos mencionar o fato de a revista Veja também veicular discursos relacionados ao contexto esportivo nacional e, de modo pontual para a presente investigação, construir uma representação social de atleta do judô brasileiro, quando afirma em uma de suas reportagens que: "desde as conquistas obtidas em 1984, o judô passou a ser uma fonte constante de alegrias para quem gostava de ver atletas brasileiros triunfando" (ARRANCADA PARA SEUL, 24 de agosto de 1988, p. 78).

\footnotetext{
${ }^{6}$ Guilherme Paranaense, tenente do exército brasileiro, venceu a prova de Tiro Rápido (ou Pistola de Velocidade) e transformou-se no primeiro atleta sul-americano a conquistar a medalha de ouro.

${ }^{7}$ Douglas Vieira, 24 anos, da categoria meio-pesado, conquistou a medalha de prata, Luiz Onmura, 24 anos, da categoria peso leve, e Walter Carmona, 27 anos, peso médio, ficaram ambos com medalhas de bronze.
} 
A fim de construir uma nova representação olímpica acerca do judô, as reportagens parecem buscar uma aproximação do público com os atletas, a fim de produzir sentimentos de apropriação e pertencimento. Dentre as representações veiculadas pela revista Veja estava a relação com a família. As referências relacionadas a esta categoria, tiveram seus primeiros indícios em 1984, ano da edição dos JO de Los Angeles. A revista Veja descreveu em detalhes, a experiência da família do judoca Luiz Yoshio Onmura, com a conquista da medalha de bronze. Segundo a reportagem, enquanto Onmura vibrava na Vila Olímpica de Los Angeles, em São Paulo, seus pais dormiam sem sonhar com uma vitória do filho. Após desencontros e tentativas, o pai do atleta, Toshikazu Onmura e sua mulher Mary, receberam a notícia da conquista do filho por meio de um telefonema, pouco depois da meia-noite. "Não consegui contar a novidade à minha família", registrava a reportagem, que sugeria certo descontentamento de Onmura com o episódio, mas sobre a conquista, realçou o comentário do pai: "Ele nunca foi de perder". Observa-se que as representações construídas pela revista exaltam uma família unida, que comemora junto, mesmo à distância.

A família, enquanto provedora de recursos e financiadora de sucesso, foi apresentada na figura de Walter Carmona, também medalha de bronze em Los Angeles: "Para o pai, a situação, mais que isso, é motivo de grande satisfação. "Tenho orgulho de sustentar um campeão", afirma Pedro José Carmona, 57 anos". A trajetória de Walter Carmona no judô, desde a infância até as vitórias "que o tornam o mais premiado judoca brasileiro", foi enfatizada pela Veja. Além disso, deu-se destaque aos estudos na faculdade de Engenharia e a nova condição do judoca: noivo e, em seguida, responsável pelo sustento da sua nova família. Para tal, largaria os tatames e passaria à administração da fábrica do pai. Do mesmo modo que as relações familiares foram apontadas como justificativa de abandono da carreira esportiva, em reportagem veiculada ainda em 1984, a falta de recursos para permanecer no esporte também é corroborada:

\begin{abstract}
O esporte está dividido entre os que recebem verbas da empresa privada e os que não recebem, resume o lutador de Judô Walter Carmona, 27 anos, medalha de bronze em Los Angeles. De um lado está o judoca Douglas Vieira, 24 anos, medalha de prata na categoria dos meio-pesados. Concentrado na preparação para as Olimpíadas, Vieira teve de afastar-se da faculdade de Educação Física da Universidade de São Paulo e equilibrar, precariamente, os horários de seus três empregos para treinar, desde janeiro, 6 horas por dia. "Minha esperança está no patrocínio", afirma o judoca. "Se me derem oportunidade de treinar 6 horas por dia até Seul, garanto que volto com uma medalha, possivelmente a de ouro" (RUMOS INCERTOS, 22 ago. 1984).
\end{abstract}

Tal referência remete a uma conformação que emergia enquanto possibilidade no cenário esportivo brasileiro, atrelada aos tempos que antecederam a abertura política do país: o incentivo financeiro de cunho privado, ou, os patrocínios (OLIVEIRA, 2012). Como afirma Linhales (1996, p. 166), "o esporte de altorendimento, que até então se encontrava controlado apenas pela estrutura de poder do sistema esportivo formal, passa, agora, a incorporar a iniciativa privada e os seus interesses econômicos".

Na construção de um judô brasileiro para brasileiros, apostava-se, ainda, no crescimento da modalidade e destacavam-se performances e conquistas de medalhas. Em reportagem sobre os JO de Seul (Coréia do Sul), em 1988, cita-se um comentário do então treinador da equipe brasileira, Geraldo Bernardes, à Veja: "Ganhamos mais de 200 medalhas em torneios internacionais nos últimos quatro anos" (ARRANCADA PARA SEUL, 24 ago. 1988, p. 78). A referida fala assinala uma história positiva do judô, denotando a ascensão do esporte por meio de um discurso que vinha sendo construído com certa consistência, vinculado ou não, aos "olhos de uma olimpíada" (ARRANCADA PARA SEUL, 24 ago. 1988, p. 78). Dando continuidade, a reportagem da revista, ainda declara: "Na verdade, o Judô nacional vem obtendo bons resultados em provas internacionais há anos, e seu rendimento tende a melhorar". Geraldo Bernardes não era apenas o treinador da equipe de judô, era um brasileiro "carioca" treinador do judô brasileiro (GOLPES MAGISTRAIS, 5 out. 1988, p. 50).

Nos JO de Seul o judô brasileiro conquistou sua primeira medalha de ouro, tendo como protagonista o judoca Aurélio Miguel (FAIXA PRETA, 19 out. 1988). Segundo a reportagem, Aurélio Miguel teria dito após a conquista: "Foi demais para mim, que sou patriota, ver a bandeira brasileira tremulando mais alto e o Hino Nacional sendo executado pela primeira vez em Seul" (GOLPES MAGISTRAIS, 5 out. 1988, p. 51). A medalha de ouro, para a revista Veja, espelhava "a imensa popularização do esporte brasileiro". Comparando-se as 
representações cunhadas no periódico antes da conquista da medalha - um esporte em ascensão - e após a medalha de ouro - um esporte consolidado - exprimem um interesse da revista e, possivelmente, pelo seu meio social, de dar a ler e a ver para os brasileiros e para o mundo o judô dos brasileiros para brasileiros.

Esse bom desempenho reflete a popularização do Judô no Brasil. Há muito tempo ele deixou de ser o esporte dos nisseis de São Paulo - no time olímpico brasileiro há apenas um descendente de japoneses, o peso leve Luis Onmura - para se tornar uma modalidade disseminada por todo o país (GOLPES MAGISTRAIS, 5 out. 1988, p. 53).

Outra representação desvelada anuncia a construção da imagem de atleta brasileiro que treina em busca do melhor desempenho e deve servir de exemplo para as crianças e jovens da nação. Em uma reportagem de quatro páginas, o feito de Aurélio Miguel é exaltado e a figura de um campeão é constituída. "Aurélio Miguel, paulista de 24 anos, amante do mar, estudante bissexto de Administração de Empresas, tornava-se o primeiro judoca campeão olímpico do país em todos os tempos e o ganhador da primeira medalha de ouro do Brasil em Seul" (GOLPES MAGISTRAIS, 5 out. 1988, p. 50). O judô é qualificado como um esporte com "ênfase na disciplina, no autocontrole e no companheirismo" e de "custo barato", atraindo, segundo a revista, primeiro aos pais. A reportagem é concluída com um anseio por "novos praticantes e futuros campeões" (GOLPES MAGISTRAIS, 5 out. 1988, p. 53).

\section{CONSIDERAÇÕES FINAIS}

A versão acerca dos judocas olímpicos apresentada pela revista Veja, no período delimitado entre os anos de 1972 a 1988, evidencia representações sociais particulares sobre pessoas e momentos vivenciados pelo judô brasileiro, que se entrelaçam com o espaço social daquele tempo. Evidenciou-se que, em um primeiro momento, a participação do Brasil no judô em Jogos Olímpicos foi considerada insuficiente. Apesar de conquistar uma medalha de bronze logo na primeira participação, as reportagens mostram-se atreladas àquilo que não foi conquistado, à derrota. Essa relação, por sua vez, pode ser justificada em relação ao momento político que o Brasil vivia, o qual buscava consolidar o país enquanto potência mundial no esporte e distanciarse, portanto, de qualquer representação de derrota. A medalha de bronze, ou o terceiro lugar na competição, parecia não estar simbolicamente atribuído a um valor de vitória.

No decorrer dos anos, as conquistas do judô atrelaram novos sentidos à prática, e o esporte antes identificado como "japonês" passou a ser admitido e representado enquanto esporte nacional, observando-se, também, uma mudança de perspectiva do fracasso para uma assimilação de vitórias. Prognósticos sobre lugares ao pódio seguiam a figura dos judocas com certa descrença até a edição dos JO de Los Angeles (1984), quando o Brasil conquistou sua primeira medalha de prata. No entanto, a partir dos JO de Seul (1988) e a conquista da medalha de ouro de Aurélio Miguel, o judô passou a ocupar papel de destaque nas páginas da revista Veja daquele ano, demonstrando uma transformação nos discursos, com ressignificações das representações sociais construídas e propagadas pelo periódico.

Em suma, compreende-se que a revista Veja, por ser um instrumento midiático, que utiliza discursos para alcançar a população, deve ser analisada com criticidade, pois muitas vezes traz imagens estereotipadas, distorcidas ou fragmentadas. Deste modo, é necessário atentar-se para a superficialidade e parcialidade dos discursos e suas consequentes repercussões. Por fim, destaca-se que não foi a pretensão do presente estudo esgotar as compreensões acerca do fenômeno estudado, mas sim de apresentar uma leitura argumentada sobre representações sociais construídas pela revista Veja, em um período determinando, acerca de um esporte olímpico que vem ganhando cada vez mais espaço na mídia brasileira, o judô.

\section{REFERÊNCIAS}

A GUERRA ESQUENTOU. Revista Veja. Sessão Esporte/23 de abril, 1980. Editora Abril, no 607, p. 90.

A OUTRA MEDALHA. Revista Veja. Sessão Esporte/13 de setembro, 1972. Editora Abril, no 210, p. 72. 
AMARO, F. O Jornal do Brasil e a representação dos atletas brasileiros nos Jogos Olímpicos: notas de uma pesquisa. Estudos em Jornalismo e Mídia, Florianópolis, v. 11, n. 2, p. 472-83, 2014.

AMORIM, P. H. O quarto poder. São Paulo: Hedra, 2014.

APRENDER ANTES DE COMPETIR. Revista Veja. Sessão Esporte/13 de setembro, 1972. Editora Abril, no 210 , p. 68-72.

ARRANCADA PARA SEUL. Revista Veja. Sessão Olimpíada/24 de agosto, 1988. Editora Abril, no 34, p. 78.

BARDIN, L. Análise de conteúdo. São Paulo: Edições 70, 2011.

BARROS, E. P. A construção do sucesso na revista Veja. 2010. 133f. Dissertação (Mestrado em Comunicação e Semiótica) - Pontifícia Universidade Católica de São Paulo, São Paulo, 2010.

BRASILEIROS: AS MEDALHAS GANHAS POR ACASO. Revista Veja. 28 de julho, 1976. Editora Abril, no 412, p. 114

CAMPOS, R. D. de. No rastro de velhos jornais: considerações sobre a utilização da imprensa nãopedagógica como fonte para a escrita da História da Educação. Revista Brasileira de História da Educação, Campinas, v. 12, n. 1, p. 45-70, 2012.

COIMBRA, C. M. B. Media and production of ways of existence. Psicologia: Teoria e Pesquisa, Brasília, v. 17 , n. 1, p. 1-4, 2001

DALMÁZ, M. A imagem do Terceiro Reich na Revista do Globo (1933-1945). Porto Alegre: Edipcrs, 2002.

FAIXA PRETA. Revista Veja. 19 de outubro, 1988. Editora Abril, no 42, p. 43.

GOLPES MAGISTRAIS. Revista Veja. Sessão Olimpíada/05 de outubro, 1988. Editora Abril, no 40, p. 50-53.

JODELET, D. Representações sociais: um domínio em expansão. In: JODELET, D. (Org.). As representações sociais. Rio de Janeiro: Eduerj, 2001, p. 17-44.

LINHALES, M. A. A trajetória política do esporte no Brasil: interesses envolvidos, setores excluídos. 1996. 242f. Dissertação (Mestrado em Ciência Política) - Faculdade de Filosofia e Ciências Humanas, Universidade Federal de Minas Gerais, Belo Horizonte, 1996.

LUCA, T. R. História dos, nos e por meio dos periódicos. In: PINSKI, C. (Org.). Fontes históricas. São Paulo: Contexto, 2010. p. 23-80.

MISSIAS-MOREIRA, R. Diálogos possíveis sobre a teoria das representações sociais. In: MISSIAS MOREIRA, R.; SALES, Z. N.; FREITAS, V. L. C.; VALENÇA, T. D. C. (Orgs.) Representações sociais, educação e saúde: um enfoque multidisciplinar. Curitiba: CVR, 2017. p. 15-24.

MOSCOVICl, S. Representações sociais: investigações em psicologia social. 11. ed. Petrópolis: Vozes, 2015.

NUNES, A. V. A influência da imigração japonesa no desenvolvimento do judô brasileiro: uma genealogia dos atletas brasileiros medalhistas em Jogos Olímpicos e campeonatos mundiais. 2011. 197f. Tese (Doutorado em Pedagogia do Movimento Humano) - Escola de Educação Física e Esporte, Universidade de São Paulo, 2011.

NUNES, A. V; RUBIO, K. As origens do judô brasileiro: a árvore genealógica dos medalhistas olímpicos. Revista Brasileira de Educação Física e Esporte, São Paulo, v. 26, n. 4, p. 667-78, 2012.

NUNES, V. A.; KOSMANN, T. F.; SHOURA, L. M. Judô no Rio Grande do Sul. In: MAZO, J. Z.; REPPOLD FILHO, A. R. (Org.). Atlas do Esporte no Rio Grande do Sul. Porto Alegre: CREF2/RS, 2005, p. 33-34.

O COMEÇO DA ORGANIZAÇÃO. Revista Veja. Sessão Esportes/23 de agosto, 1972. Editora Abril, no 207, p. 45

OLIVEIRA, M. A. T. de. Esporte e política na ditadura militar brasileira: a criação de um pertencimento nacional esportivo. Movimento, Porto Alegre, v. 18, n. 04, p. 155-174, 2012.

OS INEXPERIENTES DE MUNIQUE. Revista Veja. Sessão Esporte/6 de setembro, 1972. Editora Abril, 
№ 209, p. 97-98.

PARIZOTTO, P. G. G.; SILVA, A. F. Z. da; HEROLD JÚNIOR, C.; STAREPRAVO, F. A. O processo de institucionalização e regulamentação das artes marciais orientais no Brasil. Caderno de Educação Física e Esporte, Marechal Cândido Rondon, v. 15, n. 1, p. 53-62, 2017.

PIMENTEL, A. O método da análise documental: seu uso numa pesquisa historiográfica. Cadernos de Pesquisa, São Paulo, n. 114, p. 179-195, 2001.

RAUTENBERG, E. A revista Veja durante a ditadura civil-militar brasileira: uma discussão a respeito do seu papel no campo do poder e da luta de classes. Em Debate, Revista Digital, Florianópolis, n. 5, p. 64-85, 2011. Disponível em: <https://periodicos.ufsc.br/index.php/emdebate/article/viewFile/19803532.2011n5p64/19853>. Acessado em: 12 de dezembro de 2017.

RUBIO, K. O trabalho do atleta e a produção do espetáculo esportivo. Revista Electrónica de Geografía y Ciencias Sociales. Universidad de Barcelona, v. 6, n. 119, 2002. Disponível em: <http:// www.ub.edu/geocrit/sn/sn119-95.htm>. Acessado em: Acesso em 28 de setembro de 2017.

RUMOS INCERTOS. Revista Veja. 22 de agosto, 1984. Editora Abril, no 833, p. 48.

SILVA, E. F. G ; SANTOS, S. E. B. O impacto e a influência da mídia sobre a produção da subjetividade. In: XV ABRAPSO, 2009. Anais... XV ABRAPSO, Maceió, Faculdade Integrada Tiradentes, 2009.

SÓ SURRAS. Revista Veja. 04 de agosto, 1976. Editora Abril, nำ 413, p. 100.

TABORDA DE OLIVEIRA, M. A. Esporte e política na ditadura militar brasileira: a criação de um pertencimento nacional esportivo. Movimento, Porto Alegre, v. 18, n. 04, p. 155-174, 2012.

TEIXEIRA, G. N.; DUARTE, M. Noções gerais acerca do uso da imagem de atleta profissional. Seminário Internacional de Demandas Sociais e Políticas Públicas na Sociedade Contemporânea, n. 11, 2014.

VITÓRIAS NO TATAME. Revista Veja. 15 de agosto, 1984. Editora Abril, no 832, p. 46, 60.

ZICMAN, R. História através da imprensa: algumas considerações metodológicas. Revista do Programa de Estudos Pós-Graduados em História/PUCSP, São Paulo, n. 4, p. 90, 1985.

Autor correspondente: Josiana Ayala Ledur

E-mail: josiled@hotmail.com

Recebido: 20 de março de 2018.

Aceito: 05 de junho de 2018. 